\title{
THE EVALUATION OF EDUCATIONAL BENEFITS OF ONLINE LEARNING TOOLS ON STUDENT PERFORMANCE IN A MAJOR ASSESSMENT ITEM ACROSS TWO HIGHER EDUCATION INSTITUTIONS IN AUSTRALIA
}

\author{
Abdullah Karaksha ${ }^{1}$, Russ Chess-Williams ${ }^{3}$, Candice Holani ${ }^{1}$, Andrew K. \\ Davey $^{1}$, Shailendra Anoopkumar-Dukie ${ }^{1}$, Gary Grant ${ }^{1}$, Anthony V. Perkins ${ }^{2}$, Niru \\ S. Nirthanan ${ }^{2}$, Catherine McDermott ${ }^{3}$ \\ ${ }^{1}$ School of Pharmacy, Griffith University, Queensland (AUSTRALIA) \\ ${ }^{2}$ School of Medical Science, Griffith University, Queensland (AUSTRALIA) \\ ${ }^{3}$ School of Health Science, Bond University, Queensland (AUSTRALIA)
}

\begin{abstract}
Background: Online learning tools (e-tools) offer a number of inherent features such as independence of time of learning. However, despite several decades of research in the use of computers in education, recent studies show that e-tools implementation has not been as extensive as expected.

Purpose: The purposes of this study were to: evaluate the educational benefit of e-tools, designed and produced in-house, on student performance in a major assessment item for pharmacology curriculums in two universities, and evaluate the importance of aligning the objectives of the course with the e-tool content.
\end{abstract}

Methods: A retrospective, qualitative and quantitative study was conducted to evaluate the impact of adding e-tools, as supplements to the pharmacology curriculums in 2012, on student learning across two Australian universities; Griffith and Bond. Student attitudes towards the e-tools were assessed using a survey. Student uptake of the e-tools was evaluated by the Blackboard data. Finally, student performance in the first major assessment exams, after the deployment of the e-tools, was analysed in two academic years (2011 versus 2012) to evaluate the improvement in learning at each university.

Results: Overall, students preferred the addition of e-tools to supplement their standard curriculum. The uptake of the e-tools was significantly higher at Bond compared to Griffith. However, students from Griffith performed significantly better in the 2012 exam when compared to 2011. No significant difference in performance was observed at Bond across the two academic years.

Conclusions: Students have a positive attitude towards the implementation of e-tools as supplements to the standard curriculum. However, e-tools should be aligned with the course aims and objectives to be effective in student learning.

Keywords: E-tools, Pharmacology education, constructive alignment.

\section{INTRODUCTION}

Pharmacology is considered a core course for almost every health school in the world [1]. Over the years, pharmacology has undergone rapid expansion and discoveries, the number of United States Food and Drug Administration-approved drugs has increased, patients have become more educated and demanding, and more adverse drug events and interactions have been reported [2]. This information is debated as necessary for all health-related students, and the United Kingdom General Medical Council has called for the development of a new pharmacology curriculum that encompasses the core knowledge and skills [3]. The expansion in our knowledge of the discipline has placed more pressure on pharmacology educators to continuously incorporate new facts and update their curriculum [4]. But, while it is essential to add this new content into existing pharmacology curricula because of its relevance to contemporary clinical practice, in most instances, no additional teaching time is allocated for its inclusion [5]. This disproportionate increase in content within the limitations of existing contact hours may hinder student learning, limit comprehension and understanding, and restrict the integration of new information into students' existing knowledge-base [6]. To effectively address this issue, clinical pharmacologists and educators have identified the use of technological advancement (e-tools) as self-directed learning programs $[3,7]$. E-tools have been implemented in different undergraduate curriculums as they assist academics and educators to meet the growing 
needs and expectations for improving the quality of pharmacology education [1, 3, 7]. This new teaching method encourages the movement from a teacher-focused approach to student-focused one $[8,9]$, because e-tools are constantly accessible by students at their preferred times, help them have active learning experiences, and engage them in the learning process [10]. Moreover, some studies have found that e-tools help students undertake a deep learning approach and progress into independent life-long learners $[4,6,11,12]$. Further, a large body of research suggest that this progression is essential for successful teaching [13-15].

Yet, while e-tools offer a number of inherent features such as independence of place and time, adaptability to diverse learning styles and paces of the students or scalability to rising student numbers, their use remains limited. Despite several decades of research and development in and around the use of computers in education, recent studies show that e-tools implementation has not been as extensive as expected [16-18]. This may be due to misinterpretation of the literature for etools effectiveness, miscommunication between e-tool developers and the educators who make decisions about their use, the paucity of knowledge regarding how to integrate e-tools effectively into higher education, and economic factors such as high costs and time requirements for the generation of e-tool content $[17,19]$. Thus, there is a need for research to overcome these challenges and maximise the potential of e-tools to assist in the teaching of students. Our team has aimed to address some of these issues by designing a series of e-tools to complement the delivery of pharmacology content within the framework of a defined pedagogy. The e-tools content encompassed the basic mechanisms of action for different drug classes and was aligned with the objectives of the Human pharmacology course (3028PHM) at Griffith University. This alignment aimed to form a system which operates well for the benefit of students [15]. These e-tools were used as supplement to traditional face-to-face lectures in pharmacology courses at two higher education institutions namely: Griffith University and Bond University, Gold Coast, Australia.

The aims of this project were to: a) evaluate the educational benefit of the e-tools on student performance in a major assessment item for pharmacology curriculums in two different higher education institutions, and b) evaluate the importance of aligning the objectives of the course with the e-tool content.

\section{METHODOLOGY}

This investigation was conducted at the School of Pharmacy, Griffith University and School of Health Science, Bond University, both located on the Gold Coast, Queensland, Australia.

A suite of e-tools was designed for the pharmacology curriculums in these institutions in semester two of 2012. The e-tools were used as supplement to the standard curriculum (Figure 1). Ethical approval was granted by Griffith University Human Ethics Committee (protocol PHM/05/10/HREC) and Bond University Human Ethics committee (protocol RO1544). 


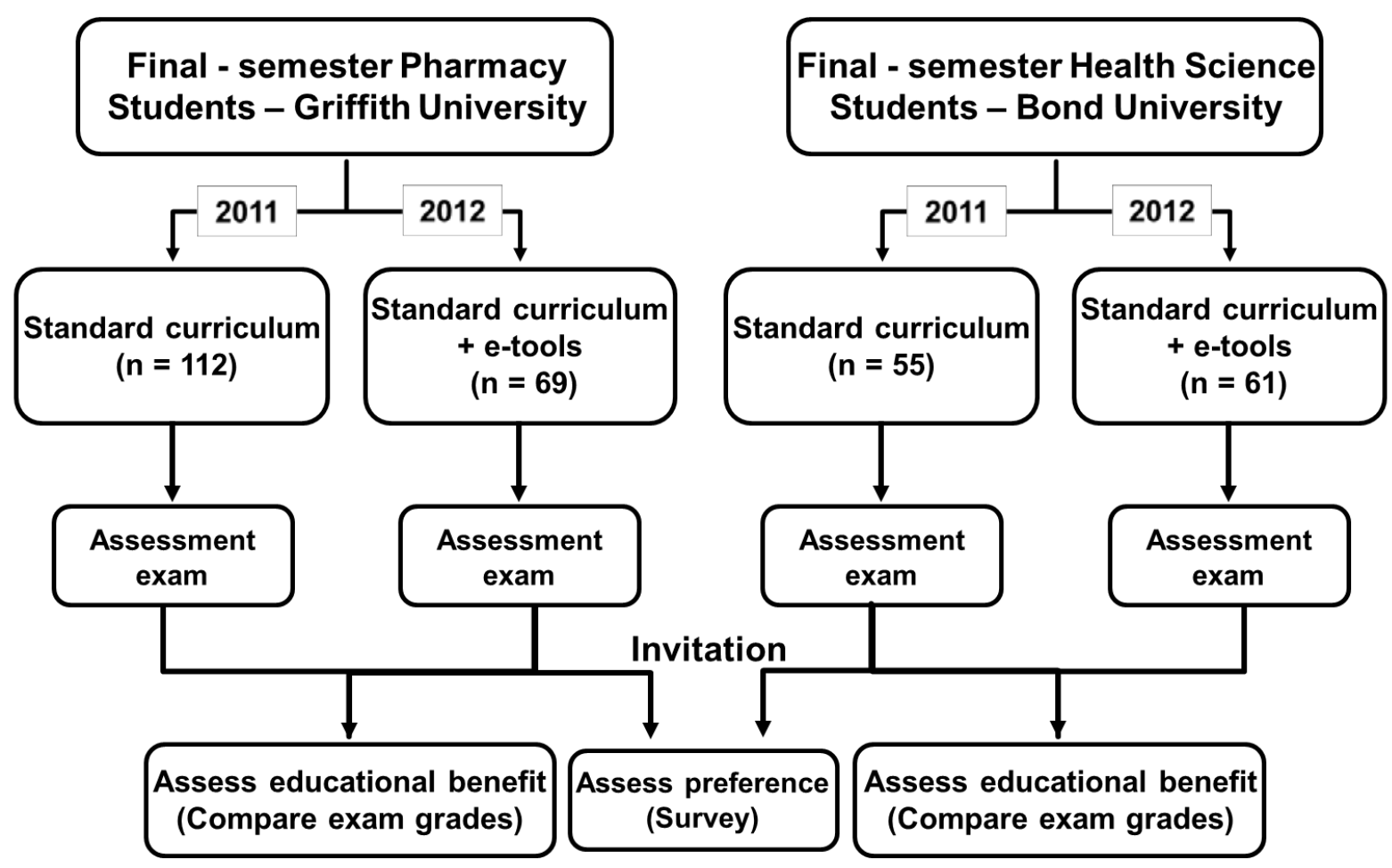

Figure 1. Study design. A suite of e-tools was deployed across two higher education institutes (Bond \& Griffith Universities) to supplement the standard pharmacology curriculum in 2012. The standard curriculum includes: lectures, workshops and/or tutorials. Student performance in a major assessment item was assessed across two academic years (2011 vs 2012) to evaluate the educational benefit of the e-tools on student learning. Student preference of the e-tools was assessed through a survey. 22 students from Griffith and 11 from Bond voluntary participated in the survey.

\subsection{E-tool design}

Custom animations were sequenced in Microsoft PowerPoint 2010 and narration was added using iSpring Pro 6.1.0 to produce the embedded animation and then convert the animations into a Flash format for ease of delivery and access through Blackboard [20]. Participants could easily control the speed of the final e-tools, skip content, and move forward and backward as needed to revisit specific concepts. The full information about the design process for our in-house e-tools within the framework of a defined pedagogy and relevant teaching theories has previously been published [20].

\subsection{Implementing the e-tools}

The e-tools were made available to students via the pharmacology courses websites using the Blackboard interface - 2012. Students were informed about the e-tools by the chief investigator during the course introductory lecture and were reminded on different occasions at lectures and tutorials. Full details of the study were made available to students via the course Blackboard site. Finally, announcements and emails were also sent to remind the students about the study and encourage them to use the e-tools. This procedure was followed at both, Griffith and Bond Universities.

\subsection{Survey to assess student attitude towards the e-tools}

A survey was designed to obtain student demographic data and evaluate their preference for the etools at both universities.

At the School of Pharmacy, Griffith University: A paper-based approach was followed when distributing the survey. Students were approached in person to participate in the survey during one of the Human pharmacology workshops. The timing of the survey gave the students the chance to access the e-tools and ensured that all students would have the opportunity to participate in the survey. Student participation in the survey was voluntary and anonymous. More details about the survey and student responses can be found in recent studies that were published by our group [21, 22] 
At the School of Health Science, Bond University: An online-based approach was used to make the survey available to students. The survey was uploaded on the Blackboard course website and student participation was invited by emails and announcements. The online survey was made available for the students during the semester. Student participation in the survey was voluntary and anonymous.

The survey was designed according to previous studies that examined student preference towards technology [18, 23-25] and obtained demographic data including gender, frequency of attending lectures, and difficulty of following topics that cover drug mechanisms of action. Additionally, students were given the opportunity to provide their perception, feedback, and additional comments in an openend question. Student preference for technology, in general, was examined by way of a five-point Likert scale (strongly agree, agree, no comment, disagree and strongly disagree). Student learning styles were assessed by asking students whether they remember words and/or pictures in responding to questions related to drug mechanisms of action.

\subsection{Assessment}

The pharmacology curriculums had different foci in each school. Thus, to evaluate the educational benefits of the e-tools on student learning, our team analysed student performance in the first main assessment item following the deployment of the e-tools, across two academic years, namely 2011 versus 2012. Students in 2011 studied the pharmacology standard curriculum which consisted of lectures, tutorials and workshops. In 2012 the e-tools were added as a supplement to the same standard pharmacology curriculum.

The assessment exams at both institutions consisted of a mix of well-constructed multiple choice, short answer and essay questions. Questions were carefully developed to assess the courses' stated learning objectives and attempted to evaluate the four levels of the knowledge dimension, namely: factual, conceptual, procedural, and metacognitive knowledge, as defined by Bloom's taxonomy and Bloom's revised taxonomy [26, 27]. Therefore, the comparative performance at the 2011 and 2012 exams was considered as a measure of the impact of e-tools on student learning.

\subsection{Data analysis}

For the survey results, a number of quantitative analyses were undertaken. Demographic data including gender and English as first language, as well as student preference for technology and learning style, were compared between the students, who used the e-tools, from Bond and Griffith Universities. T-tests and Chi-square tests were used to determine whether the two groups significantly differed in these baseline variables. The survey evaluated participant attitudes towards the technology by way of a 5-point Likert scale (strongly agree, agree, no comment, disagree, and strongly disagree). To improve sample size per group, these categories were collapsed into three types of response: "positive," "neutral," and "negative" responses.

To evaluate student uptake of the e-tools, data from the online courses website (Blackboard) were obtained, including the number of hits for each e-tool along with the time and date for accessing them. The data were de-identified by the course convenors before being analysed using t-test to compare the total e-tool usage (in terms of number of hits) between the two academic institutions.

Student grades in the assessment exams were evaluated and t-tests were used to determine the improvement in performance in each school by comparing students' grades in 2011 versus 2012.

The data were statistically analysed using IBM SPSS software ( $v 20)$. Probability $(p)$ values of less than 0.05 were considered statistically significant.

\section{RESULTS}

A total of 69 pharmacy students enrolled in the Human pharmacology course in semester 2-2012 at Griffith University were compared to a cohort of 61 students from the School of Health Sciences at Bond University.

Twenty two students from the School of Pharmacy, Griffith University voluntarily participated in the paper-based survey, representing $32 \%$ of the total cohort. In contrast, only 11 students from the School of Health Sciences, Bond University completed the online survey, representing $18 \%$ of the total cohort. 
The demographic data were compared between the two schools (Table 1). Statistical analysis for demographic data showed no significant difference between the two groups in any of the comparisons.

The results found no significant difference between the two groups in the numbers of students for whom the first language was English $(p>0.05)$. Student responses were split between easy, neutral or difficult with no significant differences noted $(p>0.05)$ when asked to rate the level of difficulty they had in understanding the course content that involved drug mechanisms of action. Student attitude towards online-learning tools was also analysed and compared between the groups. Overall, the results demonstrated positive preference for the inclusion of online-learning tools into the standard curriculum. However, the majority of students, from both groups, were either negative or neutral regarding the substitution of traditional didactic lectures with online-learning tools. Student preferred methods toward learning were also compared between the groups. The majority of students from the two groups preferred using both text and animations to study drug mechanisms of action. The difference between the two groups was not statistically significant $(p>0.05$; Table 1$)$.

Table 1: Demographic data and preference towards online-learning tools

\section{Variable}

Griffith students

Bond students

(2012) $n=23(\%)$

(2012) $n=11(\%)$

Statistic, p-value

Gender:

$$
\begin{aligned}
& \text { Female }(n=19) \\
& \text { Male }(n=15)
\end{aligned}
$$

$\chi^{2}=0.55, p=0.46$

English as first language

$\begin{array}{ll}\text { Yes }(\mathrm{n}=25) & 16(70) \\ \text { No }(\mathrm{n}=9) & 7(30)\end{array}$

$$
\chi^{2}=0.69, p=0.41
$$

Difficulty of topics that cover drug MOA a

$$
\begin{aligned}
& \text { Easy }(n=9) \\
& \text { Neutral }(n=11) \\
& \text { Difficult }(n=12)
\end{aligned}
$$

$$
\chi^{2}=0.19, p=0.91
$$

Attend pharmacology lectures:

$$
\begin{aligned}
& \text { Rarely }(n=4) \\
& \text { Frequently }(n=12) \\
& \text { Always }(n=18)
\end{aligned}
$$

Preference towards online-learning tools application in $L \& T^{\mathrm{b}}$

$$
\begin{array}{lc}
\text { Positive }(n=22) & 17(74) \\
\text { Neutral }(n=8) & 6(26) \\
\text { Negative }(n=1) & -
\end{array}
$$$$
\chi^{2}=2.9, p=0.23
$$

$$
\chi^{2}=1.1, p=0.57
$$

Preference to replace traditional lectures with online-learning tools

$$
\begin{array}{lc}
\text { Positive }(n=7) & 6(26) \\
\text { Neutral }(n=6) & 5(22) \\
\text { Negative }(n=19) & 12(52)
\end{array}
$$

Online-learning tools are useful for learning MOA

$\begin{array}{lc}\text { Positive }(n=27) & 19(83) \\ \text { Neutral }(n=4) & 3(13) \\ \text { Negative }(n=1) & 1(4)\end{array}$

$$
\chi^{2}=2.0, p=0.36
$$


Online-learning tools assist in understanding MOA

$\begin{array}{lccc}\text { Positive }(n=30) & 21(91) & 9(82) & \chi^{2}=0.42 p=0.51 \\ \text { Neutral }(n=0) & - & - & \\ \text { Negative }(n=2) & 2(9) & - & \end{array}$

Online-learning tools can change the learning style

\begin{tabular}{|c|c|c|c|}
\hline Positive $(n=24)$ & $18(78)$ & $6(55)$ & \\
\hline Neutral $(n=8)$ & $5(22)$ & $3(27)$ & $\chi^{2}=0.83 p=0.36$ \\
\hline Negative $(n=0)$ & - & - & \\
\hline
\end{tabular}

Preference towards studying MOA format

$\begin{array}{lcc}\text { Animation }(\mathrm{n}=8) & 7(30) & 1(10) \\ \text { Text }(\mathrm{n}=2) & 1(4) & 1(10) \\ \text { Both }(\mathrm{n}=22) & 15(66) & 7(63)\end{array} \quad \chi^{2}=3.3 p=0.19$

This table includes statistical comparisons of demographic data and preference towards online-learning tools between two groups; students who accessed the e-tools from the school of Pharmacy, Griffith University and those from the Health Sciences school, Bond University. All demographic data and student preference towards the online tools were not significantly different between the groups.

${ }^{a}$ mechanism of action.

${ }^{b}$ learning and teaching

Students also included comments and feedback regarding the e-tools' perceived usefulness. From Griffith University, two students found the e-tools not useful because they found the information to be either too basic or took too long to view. The remaining comments were positive and can be classified into three major themes. In the first theme, students appreciated that the e-tools were a visual explanation of drug mechanisms of action (7 comments). In the second theme, the e-tools were seen as helpful for further understanding the drug mechanisms of action (4 comments). Finally, students considered it valuable because e-tools provided additional reinforcement of the lecture materials and reviewing them was more interesting than reading the lecture notes repeatedly ( 9 comments).

All students from the Bond University gave positive feedback (4 comments) that conforms to the previous themes. However, one student highlighted the fact that the e-tools went into greater details than what they were required to know. The same student added that other e-tools explained the relevant mechanisms in greater depth than what they covered in the lectures.

Data from Blackboard provided more in-depth analyses regarding student uptake of the e-tools across the two institutions. Comparing the total number of hits on e-tools between the two schools showed a significant difference in student uptake. Students from Griffith University made 1054 hits compared to 4058 hits from Bond students (Table 2). The preferred time of day for visiting the e-tools was spread across the 24 hour period. A similar trend was found in both Schools.

Table 2: Comparisons of e-tools usages between the two academic institutions

\begin{tabular}{|c|c|c|c|}
\hline Variable & Mean & SD & Statistic, p-value \\
\hline \multicolumn{4}{|l|}{ E-tools usage (total) } \\
\hline School of Pharmacy $(n=1054)$ & 16.4 & \pm 13.3 & \multirow{2}{*}{$t=13.2, p=0.0001$} \\
\hline School of Health Science $(n=4058)$ & 190.3 & \pm 40.2 & \\
\hline
\end{tabular}

This table includes statistical comparisons of mean number of hits per day on e-tools between the school of Health Sciences, Bond University and the school of Pharmacy, Griffith University. E-tools usage significantly increased in semester two when compared with semester one. The comparison showed that the first group usage was significantly lower than the second group.

Student performance in the assessment exams was compared in each school across two academic years. One hundred and twelve students enrolled in the Human pharmacology course at the school of Pharmacy, Griffith University in 2011 compared to 69 students in 2012. Students in 2012 significantly 
performed better than their peers in $2011(t=-3.3, p<0.001)$. At the School of Health Science, Bond University, 55 students enrolled in the pharmacology course in 2011 compared to 61 in 2012. There was no significant difference in student performance across those years (Table 3 ).

Table 3: Comparisons of student performance in the assessment exams (2011 vs 2012).

\begin{tabular}{|c|c|c|c|}
\hline Variable & $\begin{array}{c}\text { Standard curriculum } \\
\text { (2011) }\end{array}$ & $\begin{array}{c}\text { Standard curriculum + } \\
\text { e-tools (2012) }\end{array}$ & Statistic, $p$-value \\
\hline \multicolumn{4}{|c|}{ School of Pharmacy ( $n=112$ vs 69) } \\
\hline Exam grades (Mean, SD) & $67.8 \pm 5.2$ & $74.0 \pm 4.4$ & $t=-3.3, p=0.001$ \\
\hline \multicolumn{4}{|c|}{ School of Health Science ( $n=55$ vs 61) } \\
\hline Exam grades (Mean, SD) & $66.1 \pm 2.2$ & $66.4 \pm 2.1$ & $t=-0.75, p=0.45$ \\
\hline
\end{tabular}

This table includes statistical comparisons of student performance in the assessment exams. Students from the school of Pharmacy in 2012 significantly outperformed their peers in 2011. However, no significant difference was observed in student performance from the school of Health Sciences in 2011 vs 2012.

\section{DISCUSSION}

The aims of the study were to assess the educational benefit of the e-tools on student performance across two higher education institutions in Australia, and evaluate the importance of aligning the objectives of the course with the e-tool content. The data indicated that participants in the School of Pharmacy, Griffith University and School of Health Sciences, Bond University were not significantly different on key demographic variables.

Students who used the e-tools and participated in the survey had similar attitudes towards the application of technology into their learning and teaching. In general, students from both groups (67\%) were positive towards the addition of online-learning tools to the pharmacology curriculum. This is an expected outcome from present day students who anticipate technology to be integrated into their learning experiences $[17,28]$.

Students have various learning styles, and these affect how they engage with traditional and new teaching methods [29]. Therefore, student preference towards studying using text, animation or both was assessed in the survey. The results showed that the majority of students $(88 \%)$ preferred to study either animations or both text and animation. This finding can be linked to the qualitative comments from students who stated that they found the e-tools as a valuable visual explanation for drug mechanisms of action. It is documented in the literature that students with a visual learning style learn more easily with diagrams and using audio-visual materials over textual information [29, 30]. This serves as a good example to show the benefit of using e-tools for improving the quality of pharmacology education $[1,3,7]$.

Nonetheless, the survey results showed that only $21 \%$ of the students were positive regarding the replacement of traditional lectures with online-learning tools. Thirunarayanan et al (2011) support this finding. The authors surveyed 359 undergraduate students, and the minority (30\%) favoured using online teaching methods over attending the traditional face-to-face lectures [31]. It is an obvious trend that students still consider traditional didactic lecturers and peer interaction in the classroom as critical to their learning success [32, 33].

Students from Bond University appeared to have used the e-tools significantly more than their peers from Griffith (Table 2). Email remainders and announcements were sent to students regularly to increase their engagement with the e-tools and the frequency of this process was similar at both institutions. Previous studies demonstrated that students appreciate receiving announcements and emails about information related to their courses [21,34]. However, a further study is necessary to determine conclusively why the uptake was greater among Bond students than Griffith students; especially since the same procedure to encourage student engagement was followed in both universities and there were no significant differences in the demographic data between the groups.

Although their uptake of the e-tools was significant, on evaluating student grades in the assessment exams showed that Bond students had no significant improvement in their performance between 2011 versus 2012, before and after the supplementation of e-tools respectively. Interestingly, there was a significant improvement in student grades at Griffith University. One explanation is that the e-tool 
content, which was originally developed at Griffith University for Griffith's curriculum, was more aligned with the objectives of their Human pharmacology course (3028PHM). This is supported by a Health Sciences student comment, which noted that some e-tools covered extra materials that were not required by their curriculum at Bond University. A recent study by Charsky and Ressler (2011) concluded that commercial e-tools failed to improve student learning when included as part of their teaching and learning experiences. However, the authors noted that the content of the e-tools should be aligned with the educational objective of the course or they will not benefit student learning [35]. Thus, the lack of alignment between our in-house built e-tools and the pharmacology curriculum at Bond University might be the reason for not benefiting student learning. According to the constructive alignment theory, the curriculum should form a system that has consistency between its three major components namely; teaching materials, learning outcomes, and assessment tasks [15]. This system operates well for the benefit of students [15]. Failing to undertake this step has been suggested to cause negative influence on students' achievement [36] like that observed in our study.

The purpose of this study was to examine the educational benefit of a set of e-tools across two academic institutions. What we discovered is that the same set of e-tools might/might not improve student learning when aligned/not aligned with the course aims and objectives. Therefore, a recommendation of this study is to ensure that a constructive alignment approach has been followed when designing the content of the e-tools before application. Limitations to this study include the omission of students' grade point average (GPA) as a variable in our analyses, the small sample size, potential for non-respondent bias and self-reporting bias.

\section{CONCLUSION}

The results of this investigation suggest that students have positive attitude towards the implementation of e-tools as a supplement to the standard curriculum. However, e-tools should be aligned with the course aims and objectives to be effective on student learning and improve their performance at assessments.

\section{REFERENCES}

[1] Candler, C., M. Ihnat, and G. Huang, Pharmacology education in undergraduate and graduate medical education in the United States. Clinical Pharmacology \& Therapeutics, 2007. 82(2): p. 134-137.

[2] Zgheib, N.K., J.A. Simaan, and R. Sabra, Using Team-based Learning to Teach Clinical Pharmacology in Medical School: Student Satisfaction and Improved Performance. The Journal of Clinical Pharmacology, 2011. 51(7): p. 1101-1111.

[3] Walley, T., et al., Clinical pharmacology and therapeutics in undergraduate medical education in the UK: the future. British Journal of Clinical Pharmacology, 1994. 37(2): p. 137-143.

[4] Hughes, I., Teaching Pharmacology in 2010 - New Knowledge, New Tools, New Attitudes. Folia Pharmacol. Jpn, 2003. 122(5): p. 411 - 418.

[5] Francis, B., et al., Assessment of Online Continuing Dental Education in North Carolina. J Contin Educ Health Prof, 2000. 20(2): p. 76-84.

[6] Pahinis, K., et al., Evaluating a Blended-Learning Course Taught to Different Groups of Learners in a Dental School. J Dent Educ., 2007. 71(2): p. 269-278.

[7] O'Shaughnessy, L., et al., Teaching of clinical pharmacology and therapeutics in UK medical schools: current status in 2009. British journal of clinical pharmacology, 2010. 70(1): p. 143-148.

[8] AACP, American Association of Colleges of Pharmacy, Commission to Implement Change in Pharmaceutical Educatio "Maintaining our Commitment to Change". Am J Pharm Educ, 1993. 57: p. 366-374.

[9] Grigg, P. and C.D. Stephens, Computer-assisted learning in dentistry a view from the UK. Journal of dentistry, 1998. 26(5-6): p. 387-395.

[10] Maxwell, S.R.J., An agenda for UK clinical pharmacology: How should teaching of undergraduates in clinical pharmacology and therapeutics be delivered and assessed? British Journal of Clinical Pharmacology, 2012. 73(6): p. 893-899. 
[11] Buckridge, M., K.-L. Krause, and H. Alexander. Scholarship of Learning and Teaching. 2010 [cited 2010; Available from: http://www.griffith.edu.au/_data/assets/pdf_file/0010/119467/SOLT-GPG.pdf.

[12] Hughes, I.E., Computer-Based Learning - an Aid to Successful Teaching of Pharmacology? Naunyn-Schmiedebergs Arch of Pharmacol, 2002. 366(1): p. 77-82.

[13] Martin, E., et al., What University Teachers Teach and how they Teach it, in Teacher Thinking, Beliefs and Knowledge in Higher Education, N Hativa and P. Goodyear, Editors. 2002, Kluwer Academic Publishers: Netherlands. p. 103-126.

[14] Ramsden, P., Learning to teach in higher education: Approaches to learning. 2nd ed, ed. P. Ramsden. 2003, New Fetter Lane, London: Routledge Falmer.

[15] Biggs, J. and C. Tang, Teaching according to how students learn., in Teaching for quality learning at university. 2007, Open University Press (McGraw-Hill Education): Berkshire, England. p. 15-30.

[16] Zollner, B., et al., Pharmacases. de-A student-centered e-learning project of clinical pharmacology. Medical Teacher, 2013. 0(0): p. 1-3.

[17] Berman, N., et al., Computer-assisted instruction in clinical education: A roadmap to increasing CAl implementation. Advances in Health Sciences Education, 2008. 13(3): p. 373-383.

[18] MacLean, J., et al., Evaluation of an e-learning teaching resource: What is the medical student perspective? Focus on Health Professional Education: A Multi-disciplinary Journal, 2011. 13(2): p. 53-63.

[19] Masters, K. and R. Ellaway, e-Learning in medical education Guide 32 Part 2: Technology, management and design. Medical Teacher, 2008. 30(5): p. 474-489.

[20] Karaksha, A., et al. Development and evaluation of computer-assisted learning (CAL) teaching tools compared to the conventional didactic lecture in pharmacology education. in EDULEARN11. 2011. Barcelona, Spain.

[21] Karaksha, A., et al., Student Engagement in Pharmacology Courses Using Online Learning Tools. American Journal of Pharmaceutical Education, 2013. 77(6): p. 125.

[22] Karaksha, A., et al., Educational benefit of an embedded animation used as supplement to didactic lectures in nursing pharmacology courses. INTED2013 Proceedings, 2013: p. 42244233.

[23] Taplin, R.H., L.H. Low, and A.M. Brown, Students' satisfaction and valuation of web-based lecture recording technologies. Australasian Journal of Educational Technology, 2011. 27(2): p. 175-191.

[24] Euzent, P., et al., Assessing student performance and perceptions in lecture capture vs. face-toface course delivery. Journal of Information Technology Education, 2011. 10: p. 295-307.

[25] Chen, P.-S.D., A.D. Lambert, and K.R. Guidry, Engaging online learners: The impact of Webbased learning technology on college student engagement. Computers and Education, 2010. 54(4): p. 1222-1232.

[26] Anderson, L.W., D.R. Krathwohl, and B.S. Bloom, A taxonomy for learning, teaching, and assessing: a revision of Bloom's taxonomy of educational objectives. 2001: Longman.

[27] Bloom, B.S., Taxonomy of Educational Objectives: The Classification of Educational Goals. 1969: Longman Group United Kingdom.

[28] Yelland, N., S. Tsembas, and L. Hall, E learning: Issues of pedagogy and practice for the information age, in Introduction - learning and the learner: Exploring learning for new times, $\mathrm{K}$. P, et al., Editors. 2008, University of Wollongong. p. 95-111.

[29] Hunt, L., L. Eagle, and P.J. Kitchen, Balancing marketing education and information technology: Matching needs or needing a better match? Journal of Marketing Education, 2004. 26(1): p. 7588.

[30] Lindquist, $\mathrm{T}$. and $\mathrm{H}$. Long, How can educational technology facilitate student engagement with online primary sources?: A user needs assessment. LHT, 2011. 29(2): p. 224-241. 
[31] Thirunarayanan, M., et al. "Digital nerds" and "digital normals": Not "digital natives" and "digital immigrants". International Journal of Instructional Technology and Distance Learning, 2011. 8.

[32] Lohnes, S. and C. Kinzer, Questioning assumptions about students' expectations for technology in college classrooms. Innovate: Journal of Online Education, 2007. 5(3).

[33] Garcia, P. and J. Qin, Identifying the generation gap in higher education: Where do the differences really lie? Innovate: Journal of Online Education, 2007. 3(4).

[34] McCabe, D.B. and M.L. Meuter, A student view of technology in the classroom: Does It enhance the seven principles of good practice in undergraduate education? Journal of Marketing Education, 2011. 33(2): p. 149-159.

[35] Charsky, D. and W. Ressler, "Games are made for fun": Lessons on the effects of concept maps in the classroom use of computer games. Computers and Education, 2011. 56(3): p. 604615.

[36] English, F.W. and B.E. Steffy, Deep curriculum alignment : creating a level playing field for all children on high-stakes tests of educational accountability. 2001, Lanham, Md.: Scarecrow Education. 